\title{
Navigating the Insight of Gender Disparity Issues in Tourism: A Conceptual Study
}

\author{
Ishita Mitra* and Mallika Sankar $\mathrm{M}^{\dagger}$
}

\begin{abstract}
Tourism experience has been perceived traditionally in terms of products, destinations, and consumption patterns. However, modern travelling is seen as an experience, performance, surveillance, play, relationship, and a form of mobility. Research studies in tourism explored gender as a global phenomenon of biased consequence. This paper attempts to conceptualize the agreements relating to 'tourism is a gender determined activity. Further, investigates the most crucial gender trends affecting tourist destination, like subjectivity and critically examines the premise that destination is actually a perceptual concept, interpreted by consumers and also a result of the moment, the people and motive of their travel.
\end{abstract}

Keywords: Tourism, Gender Disparity

\section{Introduction}

Gender is a part of our core identity, and gender discrimination is a well-documented fact. Studies showed that there is a strong correlation between tourism and the gender gap. Tourism is a tool for the economic, social, and political empowerment of society. Despite of such notion, tourism showcases instances where males and females are seen differently, and the notion seems to be

"Scholar, MBA (Tourism Management), School of Business and Management, CHRIST (Deemed to be University), Bengaluru, India; ishita.mitra@mba.christuniversity.in

† School of Business and Management, CHRIST (Deemed to be University), Bengaluru, India; mallika.sankar@christuniversity.in 
entertained even today. Research studies show that gender stereotyping, gender discrimination, sexual objectification, poor representation of women at professional levels, compensation of 10 to $15 \%$ less than the male counterpart scan be found in the tourism sector also. Apart from this, a large amount of unpaid work is being carried out by women in the tourism business. Women worldwide have high involvement in tourism, but due to various constraints, they cannot travel extreme. It is essential to empower women through tourism by creating opportunities to earn more so that women also could have a living with equity and dignity.

\section{Purpose}

The primary role of this study is to describe the gender biases seen in tourism industry despite the fact that it is a thriving industry in today's world. Even in developing and developed countries, women are not that active in the sense of travelling compared to men. The purpose of this research is to reveal the social stratification and structure, which have caused gender stereotyping even in travelling. Who would have thought that travelling will be a gender-biased phenomenon, but actually travelling and the sectors associated with it are the most unseen segments where evidence of gender discrimination is acknowledged. Thus, the research expresses different attributes and variables which show different dimensions of gender behaviour and how it varies while travelling to any holiday destination. The study conveys the answers to questions of how and why there exists gender disparity in the tourism sector. The purpose of the research is to identify the elements which show the reason why women are still lag in terms of travelling. Though women have started experiencing travelling to various destination but the mode of travel and the factors of travel remains different. Moreover, the objectivity of this research shows the social and cultural structure of the community influences in the status of women in tourism. Along with socio-cultural factors, the economic context of ethnic groups also determines the potential changes in gender relationships brought by the tourism sector.

The research examines how the fastest growing and most dynamic spheres of the global tourism economy are determined by gender. 
The earlier research shows how men and women apply different criteria to make tourism destination choices and how these preferences causes the difference in terms of tourism among them. Demographic factors such as age, gender, education, and socioeconomic status are known as customer characteristics. To a certain extent, these characteristics are significant determinants of consumer behaviours. Among these characteristics, gender appears to be one of the few features that are easy to recognize and access and is a large enough segment to be profitable for market strategy (Anderson, L.F. \& Littrell, M.A., 1995).

Therefore, this framework seeks to exploit the elements of gender disparity in the tourism industry. The study has been undertaken in order to understand and analyse the gender inequalities in the tourism industry. The study helps in revealing the status of women in such a growing industry. The study also aims at developing a conceptual model signifying the linkage between the elements of gender disparity and service outcomes that can be studied in the future using an empirical model. A comprehensive note on the role of gender and its effects on the different preference of holiday destinations and other segments are helpful for coordinators of the tourism sector.

\section{Literature background}

Anderson \&Latrell (1995) in their study, have identified how tourism transmits gender inequality issues. The study classifies that the number of trips, overnight stays, and the values for travel expenditure varies in terms of males and females as males have more opportunities for having both leisure and professional activities. It also stated that women get manifested in terms of both professional and leisure tourism. The article highlights that gender differences are prevailing in tourism because women lack access to education, better jobs, and social facilities. Due to a lack of education and jobs, women in developing countries still lack the facilities of having access to better opportunities in terms of leisure and travel. The study also stated that women lack confidence in travelling because of issues of security and availability of amenities as women need access to proper amenities due to biological significance. Biological stages and cycles may hinder women in 
travelling to extreme places and attend travelling activities like trekking, paragliding, and other activities, whereas men on the other side have a high rate of participation in undertaking adventurous travelling. Moreover, women have an overall preference for public transportation during travel while men manifested higher preferences for autonomous means of transportation such as cars and motorbikes. The article also indicates a clear difference in travelling behaviour among men and women indicating the gender gap in relation to the obstacles to travel.

Carroll \& Chang, J. J. (1967) examined the effect of tourism with a complex link of gender, education, job creation, and income creation. The study examines how gender inequality creates hindrance among women in terms of income creation, which in return affects the travel propensity of women. The research has enthusiastically shown the variables which creates problem among women in terms of travel. The idea of having leisure is still a kind of taboo in many underdeveloped and developing countries. In male chauvinist society; women lack agency in relation to social norms, domestic decision making, taxation, and access to services. The study also stated that education broadens the minds of people allowing many to have the ability to make decisions, plan, and selfindependence. Education helps people to break the stereotypical ideology regarding women. Education makes people understand the importance and value of women, which in turn, allows them to have access to basic human rights such as education, voting, and travelling. Education thus enhances the scope of travelling among women eliminating the gender inequalities and creating an integration of gender analysis in tourism.

To promote equality in travel propensity, it is important to understand that structural inequalities in terms of employment and income are mainly produced by patriarchy, which perpetuates gender-based differences in the form of education, employment opportunities, and income creation. Due to physical, psychological and economic abuse, women are still lagging in terms of travel as without income opportunities, the urge and propensity of travel reduce. It could thus be analysed that education, job, and income 
forms the major source of travelling. Due to a lack of social education and civic sense, women lack such power.

Tourism is a segregated industry providing women with lesser opportunities in terms of hiking, trekking, and other adventurous tours. The airline industry, for example, is a niche sector dominated by women in sales, marketing, and hospitality, while the majority of airline pilots, CEOs, and managers are men. Tour guiding is another area that has been hard for women to enter as the profession is male-dominated, and women tour guides face significant discrimination. Tourists of both genders share different professional and educational backgrounds and tend to have different needs and motives in travelling (Cliff, 1966). Generally, there are two groups of tourists' motives: one is the wanderlust that describes the tourist desire to visit the unusual places, and the second one the sunlust, which describes the tourist desire to experience the specific facilities that do not exist in the tourists' own place. Male travelers tend to participate in travelling more as a form of adventure and leisure. They voluntarily visit a place away from home to experience something which they could not get to find in their hometown. They tend to travel with an idea of experiencing new things which acts as a major factor of attracting them to a new place. Moreover, most of the adventurous trips have been taken up by men as they get the stimulant power of experiencing the dangers and outcomes of the trips. The study by Cliff mentioned that males have a higher tendency of visiting a new place as a matter of sunlust and wanderlust, whereas, females' attributes show a higher interest in culture compared to males as they learn on culture. Most of the females have a desire to choose a tourism destination that has a comfortable and relaxed atmosphere as they want to get rid of their daily routines (Dan Hassoneh, 1989). Moreover, women have a higher concern for an environment and sustainable development. This was further supported by Groth (2017), who defined that the major factors which allow the majority of the women to travel are relaxation and comfort.

According to the article by Groth, in India, the number of solo travellers has skyrocketed, but amid Instagram-worthy escapades are stories of violence, death, and discriminations. The article reveals that there have been numerous attacks on women when 
they seek to travel alone. Rape, sexual assault, molestation, abduction and eve-teasing are part of travelling when women undertake a solo trip. With such gruesomeness being faced by women, travelling has become a medium of fear for women in certain parts. Majority of the women refuse to stay in outskirts of any place owing to the fear of being sexually molested. The idea of solo traveller evolved long back, but women are still unsure owing to the safety concerns of being a solo traveller.

There are numerous significant linkages between tourism and gender. Gender dimension and related issues, directly and indirectly, impact women's employment in tourism. In many developing countries, women do not get efficient jobs related to tourism such as tour guides, cab drivers and hikers. On the other hand, tourism-related jobs easily accept men in the abovementioned jobs. Due to various gender dimensions, women cannot take part effectively in planning and management. In the end, women often become sexual object caused by the various effects of gender dimension (Meyers \&Maheswaran,1991). In many tourism destinations, prostitution has caused severe and often lifethreatening spreading diseases. Prostitution often coincides with abuse and violence against women and can have severe consequences for social integration.

It is noticed that women are prone to comfortable accommodation which could provide them with basic amenities and services. It is true that due to biological issues and other needs, women are keen towards comfort and relaxation. On the other hand, men can stay anywhere they want to; however, some men do need extra services like swimming pool, golf facilities and other recreational facilities. (Meyers \& Sternthal, 1991).

In service-oriented situations, the interactions between male to male and male to female differ as people behave differently when they interact with the same gender and with the opposite gender. Gender differences in tourism services may lead to different customer service outcomes.

It has been studied that there is a comparison between the types of transportation being chosen between males and females. According to the perspective of Mokhils (2012), females have a lower 
preference for heavy vehicles like bikes and cars for any trips, whereas men have access and accountability of only heavier vehicles. Women, on the other hand, prefer vehicles providing comfort and safety. Majority of the females lacks confidence in riding a car alone due to various psychological and social issues.

It is seen that females are more attracted to leisure kind of travelling in search of free time and stress-free days. On the other hand, males are more prone to a more active kind of travelling associated with sports and adventure. Though females are also a part of sports tourism, men have higher participation reflecting the gender discrimination seen in travelling. It is observed that due to low opportunities, the income incurred is low. As a result, the number of trips is also limited. Men spend a higher amount of money because the number of trips they take in a year is higher than the number of trips women take in a year. The facts reveal the differences in income among men and women. According to Oliver (n.d), tourism is highly determined by satisfaction levels. It is seen from the study that since men have higher participation in the tourism industry, the satisfaction level of men differs from place to place. It is seen that males have lower satisfaction in terms of cultural and educational tourism, whereas females get higher satisfaction when it is about culture and education. Due to natural constraints, females have lower satisfaction when it comes to adventurous trips.

\section{Conclusion}

The reviews show that gender disparity is exiting in terms of attitudes, perceptions and preferences towards holiday destination, travel propensity, the type of activities associated with tourism and accommodation facility. These differences are due to cultural and social structures and some specific forms of tourist products. The study examined various socio-cultural aspects of tourism to identify gender disparity. The factors identified are education, employment, income, and expenditure. It is identified that females consider each destination as more important than males and overall consistently high. Males are more selective in rating any destination. The present study also conveys that it is important for any marketer to process travel itineraries and elements somewhat 
in accordance with a different preference which may present the different needs of both males and females. If we consider different views of males and females, we could find contrasting answers. As per the findings of Meyers-Levy's, females have more votes for a holiday based on relaxation, rest and leisure, whereas men love holidays based on adventure (Meyers \&Maheswaran1991). Females love travelling with their families whereas; men have a notion of travelling alone with peace of mind. Moreover, women love visiting foreign countries and men love visiting local states and areas before visiting foreign countries. It is also being researched that women make the majority of the souvenir purchases suggesting that products preference is influenced by males' and females' different gender-based roles in society. Also, females might score consistently high on shopping and other facilities than men. Thus, the study reflects on the idea that tourism is highly determined by gender, which could be seen in the interest grounds of males and females. The attributes of any destination like facilities of water sports, golf, tennis, historical and cultural interest, scenic beauty, friendliness of people, opportunity to rest and relax, shopping facilities, variety of food, availability of entertainment, accommodation and transport costs vary as per the gender and its roles.

\section{References}

Anderson, L.F., \& Littrell, M.A. (1995). Souvenir-purchase behaviour of women tourists. Annals of Tourism Research, 22(2), 328-348.

Carroll, J.D., \& Chang, J. J. (1967). Relating preference data to multidimensional scaling solutions via a generalisation of Coomb's Unfolding Model. Murray Hills, N.J.: Bell Telephone Laboratories, Mimeograph.Springer Science \& Business Media.

Cliff, N. (1966). Orthogonal rotation to congruence. Psychology Press, Psychometrika, 31, 33-42.

Dan Hassoneh, A. (1989). The impact of destination service quality and destination environment on tourist satisfaction: afield study on Jordan's Golden Triangle for Tourists' Point of View. International Journal of Tourism Research,5(1), 23-49.

Darley, W. K., \& Smith, R.E. (1995). Gender differences in information processing strategies: an empirical test of the selectivity model in advertising response. Journal of Advertising, 24(1), 41-56. 
Henderson, K.A. (1994). Perspectives on analysinggender, women, and leisure. Journal of Leisure Research, 26(2), 119-137.

Juwaheer. (2011). Gender bias in hotel guests' perceptions of service quality: an empirical investigation of hotels in Mauritius. e-Review of Tourism Research, 9, 164-189.

Keith, S. (2019). Coles, Woolworths, and the local.Locale: The AustralasianPacific Journal of Regional Tourism Studies.

Kleiber, D.A., \& Hemmer, J.D. (1981). Sex differences in the relationship of locus of control and recreational sport participation. Sex Roles, 7, 801810. Harvard University Press.

Harrison, L.C.,Bramwell, B., Higham, J., Lane B.,\& Miller, G. (2003). Twenty-five years of sustainable tourism and the journal of sustainable tourism: looking back and moving forward. Journal of Sustainable Tourism, 25(1), 1-9.

Levant, R. F., Hall, R. J., Williams, C. M., \& Hasan, N. T. (2009). Gender differences in alexithymia. Psychology of men \& masculinity, 10(3), 190.

Laesser, C., Beritelli, P., \&Bieger, T. (2009). Solo travel: explorative insights from a mature market (Switzerland). Journal of Vacation Marketing, 15(3), 217-227.

Meyers-Levy, J., \& Maheswaran, D.J. (1991). Exploring differences in males' and females' processing strategies. Journal of Consumer Research, 18, 63-70.

Meyers-Levy, J., \& Sternthal, B. (1991). Gender differences in the use of message cues and judgments. Journal of Marketing Research, 28, 84-96.

Meyers-Levy, J., \& Maheswaran, D. (1991). Exploring differences in males' and females' processing strategies, Journal of Consumer Research, 18(1), 63-70.

Meyers-Levy. (1986). Gender differences in information processing: a selectivity interpretation. In P. Cafferata, \& A. M. Tybout (Eds.), Cognitive and affective responses to advertising, (pp. 219-260). Reading, MA: Addison-Wiley Publishing.

Mokhils, S. (2012). The influence of service quality on satisfaction: agender Comparison. Public Administration Research, 1(1), 103-112.

Twist, O., Yang, E. C. L., Khoo-Lattimore, C., \&Arcodia, C. (2017). A systematic literature review of risk and gender research in tourism. Tourism Management, 58, 89-100.

Parasuraman, A., Zeithaml, V., \& Berry, L. (1985). A conceptual model of service quality and its implication for future research (SERVQUAL). The Journal of Marketing in Tourism, 49, 41-50.

Ramchurjee, N. (2010). "Tourism" a vehicle for women's empowerment: prospect and challenges. Global Report on Women in Tourism. 
Rossiter, J. (1987, June). Market segmentation: a review and proposed resolution. Australian Marketing Researcher, 11(1), 36-58. APAIS, Australian public affairs information service

Ryan, M.M., \&Soutar, G.N. (1997). Holiday destination preferences: a perceptual space approach. ANZMEC Conference Proceedings 1, 160171.

Sheldon, P. (1989). Travel industry information systems. In S. Witt \& L. Moutinho (Eds.). Tourism marketing and management handbook (pp. 589592). New York: Prentice Hall.

Shaw, S. M. (1994). Gender, leisure, and constraint: towards a framework for the analysis of women's leisure. Journal of Leisure Research, 26(1), 822.

Swain, M. (1995). Gender in tourism. Annals of Tourism Research, 22(2), 247266. CABI.

Telisman-Kosuta, N. (1989). Tourist destination image. In S. Witt \& L. Moutinho (Eds.). Tourism marketing and management handbook (pp. 557561). New York: Prentice Hall.

Chiao, J. Y., Li, S. C., Turner, R., Lee-Tauler, S. Y., \& Pringle, B. A. (2017). Cultural neuroscience and global mental health: addressing grand challenges. Culture and brain, 5(1), 4-13. 